\title{
Pediatric glaucoma suspects
}

\author{
Karanjit Kooner' \\ Matthew Harrison' \\ Zohra Prasla' \\ Mohannad Albdour' \\ Beverley Adams-Huet ${ }^{2}$ \\ 'Department of Ophthalmology, \\ ${ }^{2}$ Department of Clinical Sciences, \\ Division of Biostatistics, University of \\ Texas Southwestern Medical Center, \\ Dallas, TX, USA
}

This article was published in the following Dove Press journal:

Clinical Ophthalmology

16 June 2014

Number of times this article has been viewed

Purpose: To report demographic and ocular features of pediatric glaucoma suspects in an ethnically diverse population of North Central Texas.

Design: Retrospective cross-sectional chart review.

Participants: Subjects included 75 (136 eyes) pediatric glaucoma suspects. Patients with one or more of the following risk factors were included: cup-to disc (C/D) ratio of $\geq 0.6$; intraocular pressure (IOP) $\geq 21 \mathrm{mmHg}$; family history of glaucoma; congenital glaucoma in the opposite eye; history of blunt trauma to either eye; and presence of either Sturge-Weber or Axenfeld-Rieger syndrome, or oculodermal melanocytosis.

Methods: Data were extracted from electronic patient medical records. Patient records with incomplete data were excluded. The main outcome measures were race, sex, age, IOP, C/D, family history of glaucoma; and glaucoma treatment.

Results: Subjects included 28 (37.3\%) Hispanics, 20 (26.6\%) African Americans, 20 (26.6\%) Caucasians, and seven (9.3\%) Asians. Forty (53.3\%) of the patients were male. Suspicious optic disc was seen in $57(76 \%)$; elevated IOP in 25 (33.3\%); presence of family history in $13(17.3 \%)$, and Sturge-Weber syndrome in nine (12\%) patients. The average C/D ratio was $0.58 \pm 0.2$. The $\mathrm{C} / \mathrm{D}$ ratios of African American (0.65 \pm 0.2$)$, Hispanic (0.63 \pm 0.2$)$, and Asian $(0.62 \pm 0.15)$ patients were significantly greater than those of Caucasians $(0.43 \pm 0.18 ; P=0.0004$, 0.0003 , and 0.0139 , respectively). Caucasian patients were the youngest ( $7.9 \pm 4.8$ years). Eleven cases (14.7\%) required medication.

Conclusion: Thirty-three point seven percent of patients seen in the glaucoma clinic were glaucoma suspects. The most common risk factors for suspected glaucoma were suspicious optic discs, elevated IOP, and family history of glaucoma. Most patients required only close observation. Long-term follow-up of these patients is warranted to determine the mechanisms of conversion to glaucoma.

Keywords: childhood glaucoma suspects, suspicious optic disc, intraocular pressure

\section{Introduction}

Glaucoma suspects, whether adults or children, are patients who may be at greater risk of developing glaucoma. The Preferred Practice Pattern ${ }^{\circledR}$ (American Academy of Ophthalmology), ${ }^{1}$ defines glaucoma suspects as patients with one or more risk factors for glaucoma in at least one eye. These include: 1) persistently elevated intraocular pressure (IOP) $\geq 30 \mathrm{mmHg}$ with normal optic nerve appearance and visual field (VF) test results; 2) suspicion of glaucomatous damage of the optic disc; and 3) VF defect indicative of glaucomatous damage in the absence of clinical signs of other optic neuropathies. ${ }^{1}$ This definition is a work-in-progress, since new risk factors or combination of factors are constantly being discovered. The Ocular Hypertension Treatment Study found that adult patients with ocular hypertension and thin central corneal thickness were at greatest risk of developing glaucoma. ${ }^{2}$ A follow-up of The Blue Mountains Eye Study showed that open-angle glaucoma risk at the 10 -year mark was about four times greater in patients who had narrow 
retinal arteries when the study began. ${ }^{3}$ Similarly, the Singapore Malay Eye Study, a population-based crosssectional study, reported that subjects with decreased retinal arteriolar venular tortuosity and small venular branching angle were more likely to have glaucoma. ${ }^{4}$ Such findings have rekindled efforts to diagnose glaucoma suspects at earlier stages and age.

There are no accurate data in the US on children with glaucoma, glaucoma suspicion, or who have lost their sight due to glaucoma because there is no national registry for the blind and visually impaired. An estimate by the American Printing House for the Blind in 2009 suggested that there were 59,355 children under the age of 21 with visual disabilities. ${ }^{5}$ An estimate from the US Bureau of the Census, which surveys approximately 295,000 households each month, reported 485,500 children under 18 with visual problems in 2013.6 Based on meta-analyses of world and US studies on childhood blindness, glaucoma accounts for $2 \%-6 \%$ of blindness in children. ${ }^{7,8}$

Identifying pediatric glaucoma suspects is fraught with significant obstacles. A complete glaucoma evaluation that includes a vision test, gonioscopy, IOP measurement, fundoscopic and VF exams is not always possible. In addition, pertinent baseline epidemiological and risk factors such as age, race, sex, family history of glaucoma, cup-to-disc (C/D) ratio, IOP, as well as treatment modalities are not well established. To study the main demographic and ocular features of pediatric glaucoma suspects, the current authors designed a retrospective cross-sectional chart review of a cohort of pediatric glaucoma suspects from an ethnically diverse population of the Children's Medical Center (CMC) in Dallas, TX, USA. This information could aid in broadening the definition of pediatric glaucoma suspects and help with early detection and management.

\section{Materials and methods}

\section{Study design}

This study is a cross-sectional retrospective chart review, not a population-based study. Participants were part of the Dallas Glaucoma Registry, which contains epidemiological data on the diagnosis and treatment of glaucoma of over 4,000 patients examined at University of Texas Southwestern Medical Center and affiliated clinics in the Northern Texas region. ${ }^{9}$ Protocol approval was obtained for the Institutional Review Board of the Dallas CMC. The protocol was in compliance with the Health Insurance Portability and Accountability Act of 1996. A search of the CMC database was conducted for cases of primary and secondary pediatric glaucoma, and pediatric glaucoma suspects seen in the eye clinic between June 2005 and June 2011. There was no direct patient contact.

\section{Participant selection}

The study defined pediatric glaucoma suspects as those patients who met at least one of the following criteria in one or both eyes: suspicious optic discs defined as a cup-to disc $(C / D)$ ratio of $\geq 0.6$; asymmetry of $>0.2$ between the two eyes; notching or narrowing of the neuroretinal rim; persistently elevated IOP of $\geq 21 \mathrm{mmHg}$; family history of glaucoma in the parents or siblings; diagnosis of congenital glaucoma in the opposite eye; history of blunt trauma to either eye; presence of conditions closely associated with glaucoma such as Sturge-Weber syndrome, ${ }^{1}$ Axenfeld-Rieger syndrome, and oculodermal melanocytosis (Nevus of Ota); and age $\leq 15$ years. ${ }^{10-12}$ Patients were excluded if: 1) clinical information was inadequate; 2) follow-up was $<3$ months; 3 ) glaucoma suspicion was a tertiary diagnosis; and 4) age $>15$.

\section{Data collection}

The following information was collected from the medical records: age; sex; ethnicity; IOP; C/D ratio obtained by direct ophthalmoscopy; family history of glaucoma; history of blunt ocular trauma, glaucoma in the opposite eye or any glaucoma related surgical intervention; high-risk glaucoma conditions such as port-wine stain birthmark suggestive of Sturge-Weber syndrome; Axenfeld-Rieger syndrome; oculodermal melanocytosis; and current glaucoma medications. Gonioscopic and VF results were not available for all patients; as such, they were excluded from analysis. Data were entered into a computer database and the information was handled according to CMC's guidelines on data confidentiality and protection.

\section{Statistical analysis}

Means and standard deviations were used to characterize quantitative variables and percentages were used to describe categorical variables. Age was compared using one-way analysis of variance; categorical patient characteristics (one observation per patient), which were compared between ethnic groups, were analyzed by Fisher's exact test. For continuous variables, comparisons of $\mathrm{C} / \mathrm{D}$ and IOP risk factors among ethnic groups included measurements from both eyes. These were analyzed using a mixedeffects linear model with ethnic group as a fixed effect. To statistically account for the correlation between the 
paired eyes of one individual, each subject was modeled as a random effect and an unstructured covariance pattern was specified. This mixed-model approach using the eye as the unit of analysis effectively allowed more information to be included in the analysis and yielded increased precision and power compared to separate analyses of right and left eyes or using one eye at random. ${ }^{13}$ Statistical analysis was performed using SAS version 9.2. (SAS Institute, Cary, NC, USA), using the MIXED procedure in particular. ${ }^{14}$ A two-sided $P$-value of $<0.05$ was considered statistically significant.

\section{Results}

Seventy-eight pediatric patients were selected; three (1.2\%) were excluded because of inadequate clinical information, resulting in 75 participants (136 eyes). Sixty-two (82.6\%) met the selection criteria for both eyes. Forty-eight (64\%) were included based on one inclusion criterion, 22 (29.3\%) met two criteria, and five $(6.7 \%)$ had three or more of the eligible criteria. Patient characteristics are shown in Table 1. Most patients $(37.3 \%)$ were Hispanic, followed by Caucasian and African American in equal numbers (26.7\%), and Asians (9.3\%).

The average age of the cohort was $8.2 \pm 4.9$ years; Caucasian patients were the youngest $(6.4 \pm 5.2$ years).
However, there were no statistically significant differences between the races $(P=0.2)$. The most prevalent glaucoma risk factor observed was suspicious optic disc. This was seen in 56 (74.7\%) patients (103 eyes). Suspicious discs were most common in Asian (85.7\%), African American (85\%), Hispanic (82.1\%), and Caucasian (50\%) patients. The average $\mathrm{C} / \mathrm{D}$ ratio was $0.58 \pm 0.2$. The $\mathrm{C} / \mathrm{D}$ ratios of African Americans (0.65 \pm 0.2$)$, Hispanics (0.63 \pm 0.2$)$, and Asians $(0.62 \pm 0.15)$ were significantly greater than for Caucasians $(0.43 \pm 0.18 ; P=0.0004, P=0.0003, P=0.01$, respectively). No statistically significant differences were found between C/D ratios of African Americans, Hispanics, and Asians.

High IOP was the second most common risk factor. It was observed in 25 (33.3\%) patients (46 eyes): three Asians (42.8\%), eight Caucasians (40\%), six African Americans (30\%), and eight Hispanics (28.6\%). However, the prevalence of high IOP and mean IOP among ethnic groups was not statistically different (overall $P$-value across all ethnic groups was $P=0.76$ ). A family history of glaucoma was most prevalent in Caucasian (25\%), African American (20\%), and Hispanic (15\%) patients. Prevalence for all risk factors based on race is shown in Table 1 and Figure 1. Eleven glaucoma patients (14.7\%) were treated with medication because their IOPs were consistently above

Table I Dallas pediatric glaucoma suspect characteristics by race and ethnicity

\begin{tabular}{|c|c|c|c|c|c|}
\hline Variable & Total & Caucasian & African American & Hispanic & Asian \\
\hline $\mathbf{N}(\%)$ & $75(100)$ & $20(26.7)$ & $20(26.7)$ & $28(37.3)$ & $7(9.3)$ \\
\hline Male & $40(53.3)$ & $9(45)$ & $13(65)$ & $15(54)$ & $3(43)$ \\
\hline Female & $35(46.7)$ & II (55) & $7(35)$ & $13(46)$ & $4(57)$ \\
\hline Age: yrs, Ist visit & $8.2 \pm 4.9$ & $6.4 \pm 5.2$ & $8.3 \pm 5.3$ & $9.5 \pm 4.6$ & $8.2 \pm 3.6$ \\
\hline Range: yrs, Ist visit & $0.0-17.1$ & $0.08-13.8$ & $0.00-14.8$ & $0.2-17.1$ & $1.8-13.4$ \\
\hline Age: yrs, last visit & $9.7 \pm 4.9$ & $7.9 \pm 4.8$ & $10.2 \pm 5.6$ & $10.8 \pm 4.7$ & $9.3 \pm 20.9$ \\
\hline Range: yrs, last visit & $0.04-18.9$ & $0.25-13.8$ & $0.05-17.8$ & $0.17-18.9$ & $5.0-13.4$ \\
\hline IOP: mmHg & $16.7 \pm 4.0$ & $17.6 \pm 4.8$ & $16.5 \pm 3.6$ & $16.1 \pm 3.6$ & $17.2 \pm 3.9$ \\
\hline$C / D \pm S D$ & $0.58 \pm 0.2$ & $0.43 \pm 0.18$ & $0.65 \pm 0.2$ & $0.63 \pm 0.2$ & $0.62 \pm 0.15$ \\
\hline \multicolumn{6}{|l|}{ Glaucoma suspicion } \\
\hline Elevated IOP & $25(33.3)$ & $8(40)$ & $6(30)$ & $8(28.6)$ & $3(42.9)$ \\
\hline Suspicious discs & $56(74.6)$ & $10(50)$ & $17(85)$ & $23(82.1)$ & $6(85.7)$ \\
\hline Family history & $13(17.3)$ & $5(25)$ & $4(20)$ & $4(14.3)$ & $0(0.0)$ \\
\hline Sturge-Weber & $9(12)$ & $5(25)$ & I (5) & $3(10.7)$ & $0(0.0)$ \\
\hline Trauma & $\mathrm{I}(\mathrm{I} .3)$ & I (5) & $0(0.0)$ & $0(0.0)$ & $0(0.0)$ \\
\hline Axenfeld-Rieger & $2(2.6)$ & I (5) & $\mathrm{I}(5)$ & $0(0.0)$ & $0(0.0)$ \\
\hline Glaucoma other eye & $2(2.6)$ & $0(0.0)$ & I (5) & I (3.5) & $0(0.0)$ \\
\hline Nevus of Ota & $2(2.6)$ & $0(0.0)$ & $0(0.0)$ & I (3.5) & I (I4.2) \\
\hline Medication Rx & $14(18.6)$ & $3(15)$ & $3(15)$ & $7(25)$ & I (I4.2) \\
\hline Prostaglandin analog & $8(10.7)$ & I (5) & $2(10)$ & $4(14.3)$ & I (I4.2) \\
\hline Beta blocker & $3(4)$ & I (5) & $0(0.0)$ & $2(7.1)$ & $0(0.0)$ \\
\hline Topical CAI & $3(4)$ & I (5) & $\mathrm{I}(5)$ & I (3.5) & $0(0.0)$ \\
\hline
\end{tabular}

Note: Continuous variables are presented as mean (SD).

Abbreviations: IOP, intraocular pressure; C/D, cup-to disc ratio; CAl, carbonic anhydrase inhibitor; yrs, years; SD, standard deviation; Rx, prescription. 


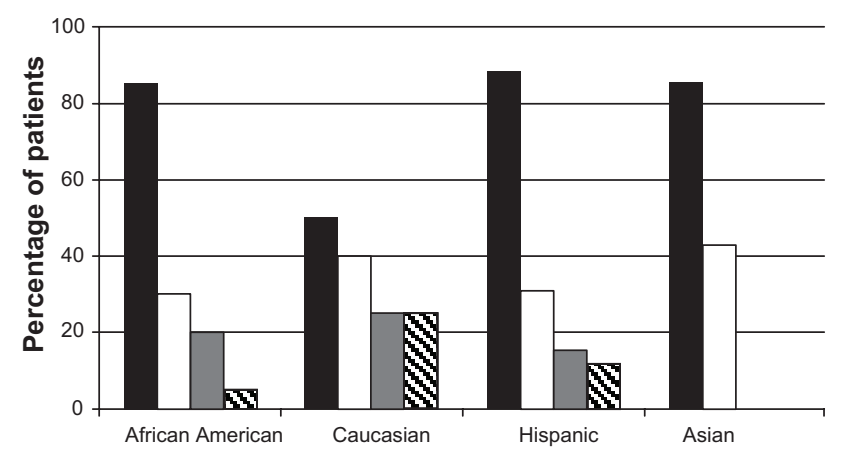

Figure I Prevalence of risk factors by race and ethnicity in the Dallas pediatric glaucoma suspects.

Note: Suspicious optic disc (black fill), intraocular pressure (unfilled), family history of glaucoma (gray fill), Sturge-Weber syndrome (hatched).

$30 \mathrm{mmHg}$. Prostaglandin analogs were regularly used in $72.7 \%$ of patients. None of the glaucoma suspects required surgery for glaucoma.

\section{Discussion}

This study highlighted important demographic and ocular information regarding pediatric glaucoma suspects in Northern Texas. The study was not population based and did not attempt to estimate incidence and prevalence rates for pediatric glaucoma suspects.

The definition of glaucoma suspect in adults and children is not well established. Sommer ${ }^{15}$ suggests discontinuing the use of the term "ocular hypertension" since it only focuses on high IOP as a precursor to glaucoma. It is well recognized that glaucoma is a multifactorial disease. As a result, risk factors other than IOP should be considered in glaucoma suspects. This is essential for pediatric patients for whom a complete ophthalmic exam is not always possible. The current study used the following factors in its definition of pediatric glaucoma suspects: family history of glaucoma; history of trauma; congenital glaucoma in one eye; Sturge-Weber syndrome; Axenfeld-Rieger syndrome; and oculodermal melanocytosis. Other conditions such as Klippel-Trénaunay-Weber syndrome, aniridia, Peters anomaly, microphthalmia, retinopathy of prematurity, persistent hyperplastic primary vitreous (persistent fetal vasculature syndrome), neurofibromatosis, uveitis, and others should be included in future studies. No patients with these diagnoses qualified for this study.

\section{Demographics}

A large proportion (82.6\%) of patients had features of glaucoma suspicion in both eyes. The majority (64\%) had one risk factor, $33 \%$ had two risk factors, and $7 \%$ had three or more risk factors. Pediatric glaucoma suspects made up an impressive $33.7 \%$ of all patients seen in the clinic. This figure corresponds well with the authors' experience with adults in Dallas, TX, USA where $39 \%$ of patients were diagnosed as glaucoma suspects as well. ${ }^{9}$ The focus of the current study was not to predict the incidence of glaucoma suspicion in children but to highlight their clinical features. A population-based study conducted in Olmstead County, MN, USA found 24 (18.75\%) glaucoma suspects in 128 patients diagnosed with childhood glaucoma. ${ }^{16}$ That study spanned 40 years and the patients were less than 20 years of age when the study commenced. The majority (95.7\%) of the participants were Caucasian, and the calculated incidence of glaucoma suspicion was 1.9 per 100,000. In the current study, no racial immunity to glaucoma suspicion in children was found. Hispanics (37.3\%) were the most common ethnic group affected, while Caucasians and African Americans (26.7\%) were equally represented, followed by Asians (9.3\%).

The Dallas-Fort Worth Metroplex is cosmopolitan and racially diverse. In 2011, the top four racial groups were Caucasian (61.1\%), African American (18.9\%), Hispanic (34\%), and Asian (3.7\%). ${ }^{17}$ The Los Angeles Latino Eye study reported a high incidence of open-angle glaucoma and ocular hypertension in the adult Hispanic population. ${ }^{18}$ Interestingly, when compared to the patient populations of the CMC clinic and the entire hospital, the suspect population was slightly over-represented by African Americans and under-represented by Hispanics (Figure 2). This appears to confirm the trend observed in adult primary open-angle glaucoma in which African Americans are more affected than other races. ${ }^{19}$

In the current study, glaucoma suspects showed no sex predilection, though there were slightly more males

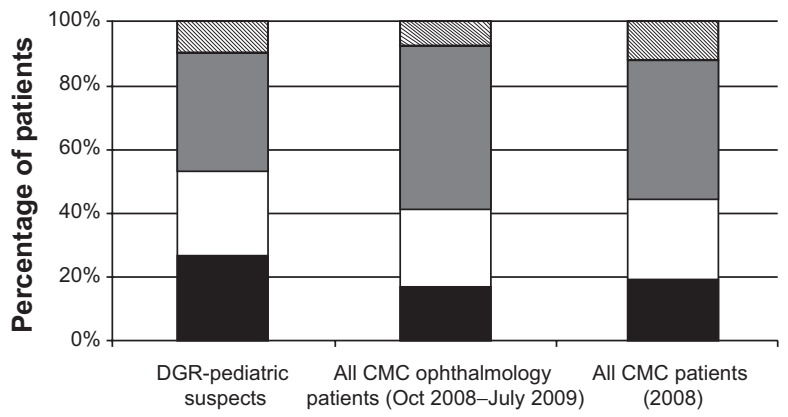

Figure 2 Distribution of patients by race and ethnicity in the Dallas Glaucoma Registry (DGR), the Dallas Children's Medical Center (CMC) Ophthalmology Clinic, and the entire Dallas Children's Medical Center.

Note: African American (black fill), Caucasian (unfilled), Hispanic (gray), Asian (hatched). 
$(40 ; 53.3 \%)$ than females $(35 ; 46.7 \%)$. Aponte et al reported more female $(16 ; 66.6 \%)$ than male $(8 ; 33.3 \%)$ patients among their glaucoma suspects. ${ }^{16}$ The average age of the current study's patients' age at diagnosis was $8.2 \pm 4.9$ years old (0.00-15), much younger than those described by Aponte et al whose patients had a mean age at diagnosis of 13.7 years (6.7-19.7 years). ${ }^{16}$ Caucasian patients were also the youngest in the current study, which could be a reflection of socioeconomic differences in health care delivery in the CMC clinic. It has been shown that low-income and non-Caucasian children have much less access to care than children from more affluent and Caucasian families, irrespective of health status and health insurance coverage. ${ }^{20}$

In the current study, a family history of any form of glaucoma was observed in Caucasian (25\%), African American (20\%), and Hispanic (14\%) patients, but absent in Asian patients. On another note, a family history of glaucoma might prompt parents to check their children early in life for glaucoma. A Saudi Arabian study reported a positive correlation between family history and congenital and secondary glaucoma in $30 \%$ of patients. ${ }^{21}$ Their data also showed a prevalence of consanguinity in $60 \%$ of patients. In adults, a family history of glaucoma was observed in $40 \%$ of adults with ocular hypertension. ${ }^{22}$

The current study included patients with Sturge-Weber syndrome because of the higher prevalence of glaucoma associated with this disease. ${ }^{10}$ In this study, $12 \%$ of patients had Sturge-Weber syndrome, and the condition was most prevalent in Caucasian children (25\%), followed by African American (5\%) and Hispanic (10\%) children, but not in Asian children.

\section{Ocular features}

Four main risk factors were identified in the current study. The most common risk factor was suspicious optic disc. It was observed in $76 \%$ of suspects, a finding that correlates with a previous study by Gordon et al using data from adult glaucoma suspects. ${ }^{2}$ A dilated fundus exam might be the easiest ocular test to perform in children. In contrast, a vision test and IOP and VF measurements are difficult to administer because they require more cooperation from the children.

In the current study, average $\mathrm{C} / \mathrm{D}$ was $0.58 \pm 0.2$. African Americans exhibited the largest C/D $(0.65 \pm 0.2)$ while Caucasians had the smallest $(0.43 \pm 0.18)$. Both Hispanic and Asian children had $\mathrm{C} / \mathrm{D}$ values somewhere between those of the Caucasians and African Americans. A 2009 study by El-Dairi et al found that average $\mathrm{C} / \mathrm{D}$ ratios in healthy children were
0.23 in African American and 0.16 in Caucasian children. ${ }^{23}$ Another study by Aponte et al showed that $21 \%$ of Caucasian children were considered glaucoma suspects based on suspicious optic discs. ${ }^{16}$

The second most common risk factor in the current study, elevated IOP, was found in $33 \%$ of patients. Caucasian suspects had the highest IOP, but this was not statistically significant compared to African American or Hispanic patients. Aponte et al found elevated IOP to be the most common $(50 \%)$ indicator of glaucoma suspicion in predominantly Caucasian pediatric glaucoma suspects. ${ }^{14}$

Some pediatric glaucoma suspects might require medical treatment because of elevated IOP $(>30 \mathrm{mmHg})$ or the presence of deep cups. Treatment can be modified as the child grows older, and more definitive tests such as VF and gonioscopy should be performed. In the current study, $14.7 \%$ of glaucoma suspects were treated medically because their IOPs were consistently $>30 \mathrm{mmHg}$. Prostaglandin analogs were the most common agents used. The British Infantile and Childhood Glaucoma Eye Study in 2007 found that 94\% of pediatric patients with primary congenital glaucoma had surgery; only $6 \%$ required medical management. ${ }^{24}$ In the same study, $86 \%$ of cases with secondary glaucoma required medical management. Medical management of glaucoma in children remains a powerful tool. A Nigerian study screened for glaucoma among 1,393 dark-skinned primary school children between 7 and 13 years of age; they found that eleven $(0.8 \%)$ were glaucoma suspects. ${ }^{25}$ Suspicious optic discs and elevated IOP were the first and second most common features. Another Nigerian study found that ten of 327 schoolchildren (3.2\%) were glaucoma suspects. ${ }^{26}$

The current study has the inherent biases associated with any retrospective study. All patients were examined at a major university children's eye hospital. Different residents and fellows examined patients over a period, potentially increasing inter-examiner error. The number of children examined did not reflect the actual prevalence of glaucoma suspects in the community. The cohort size was relatively small, especially with regard to Asian children. As such, results only provided a snapshot of glaucoma suspect features during the study period. Some useful information such as central corneal thickness, gonioscopy, and VF is lacking because of technical difficulties and non-cooperation of children. Other eye conditions such as aniridia, retinopathy of prematurity, Rubinstein-Taybi syndrome, persistent hyperplasic primary vitreous, and congenital rubella should be included in future studies, since a significant proportion of these conditions 
can lead to glaucoma. ${ }^{27}$ Due to the cross-sectional nature of the study, the authors were unable to determine changes in ocular parameters over time.

However, the study had several strengths. For example, the study included a heterogeneous mixture of Caucasian, African American, Hispanic, and Asian children. However, the authors do not recommend racial generalizations due to the small sample size of the study. The ophthalmology clinic at the CMC sees more than 20,000 patients a year. This provided a sufficient pool of potential glaucoma suspects. In addition, glaucoma management was provided by residents and fellows under the supervision of faculty members of the University of Texas Southwestern Medical Center. This assured consistent management protocols. Since many glaucoma suspects were asymptomatic, the eye clinic at the $\mathrm{CMC}$ allowed the authors to examine a wide range of children seeking relief from other eye problems. A large prospective, well-designed study with longer follow-up is required to evaluate outcomes in more detail and to identify additional risk factors in the development of glaucoma.

In summary, clinicians should be vigilant about the presence of glaucoma in children. In this study, pediatric glaucoma suspects were found in all racial groups, though they were most prevalent in the Hispanic population. Suspicious optic discs, elevated IOP, family history of glaucoma, and Sturge-Weber syndrome were the four most common risk factors. A longer follow-up of these patients is planned to better understand the natural history of the disease in children and to stimulate awareness of glaucoma suspects in the ophthalmic community and general public.

\section{Acknowledgments}

This study was supported in part by an unrestricted grant from Research to Prevent Blindness, New York, NY, USA, Visual Sciences Research Center Core Grant EY020799, and NIH CTSA Grant UL1-RR024982.

\section{Disclosure}

The authors report no conflicts of interest in this work.

\section{References}

1. American Academy of Ophthalmology Glaucoma Panel. Preferred Practice Pattern ${ }^{\circledR}$ guidelines. Primary Open Angle Glaucoma Suspect. American Academy of Ophthalmology; 2010. Available at: http://one. aao.org/preferred-practice-pattern/primary-openangle-glaucoma-ppp-october-2010. Accessed May 8, 2014.
2. Gordon MO, Beiser JA, Brandt JD, et al. The ocular hypertension treatment study; baseline factors that predict the onset of primary openangle glaucoma. Arch Ophthalmol. 2002;120(6):714-720.

3. Kawasaki R, Wang JJ, Rochtchina E, et al. Retinal vessel caliber is associated with the 10-year incidence of glaucoma. The Blue Mountains Eye Study. Ophthalmology. 2013;120:84-90.

4. Wu R, Cheung CYL, Saw SM, et al. Retinal vascular geometry and glaucoma: The Singapore Malay Eye Study. Ophthalmology. 2013;120: $77-83$.

5. American Printing House for the Blind Annual Report for 2009. Available from: www.aph.org/about/ar2009.html. Accessed February 26, 2013.

6. http://factfinder.census.gov [homepage on the Internet] US Bureau of the Census. Available from: http://factfinder.census.gov/servlet/ DatasetMainPageServlet?_ds_name=ACS_2009_1YR_G00. Accessed February 26, 2013.

7. Kong L, Fry M, Al-Samarraie M, Gilbert C, Steinkuller PG. An update on progress and the changing epidemiology of causes of childhood blindness worldwide. J AAPOS. 2012;16:501-507.

8. Gilbert C, Foster A. Blindness in children; control priorities and research opportunities. Br J Ophthalmol. 2001;85:1025-1027.

9. Kooner KS, Joseph A, Shar A, et al. Dallas Glaucoma Registry: Preliminary Results. J Clinic Experiment Ophthalmol. 2011;2:164.

10. Sharan S, Swamy B, Taranath DA, et al. Port-wine vascular malformation and glaucoma risk in Sturge-Weber syndrome. J AAPOS. 2009; 13(4):374-378.

11. Chang TC, Summers CG, Schimmenti LA, Grajewski AL. AxenfeldRieger syndrome; new perspectives. Br J Ophthalmol. 2012;96: 318-322.

12. Araie M, Chew P, RojanoPongpun P. Oculodermal Melanocytosis. J Glaucoma. 2002;11:454-457.

13. Glynn RJ, Rosner B. Regression methods when the eye is the unit of analysis. Ophthalmic Epidemiol. 2012;19(3):159-165.

14. Littell RC, Milliken GA, Stroup WW, Wolfinger RD, Schabenberger O. SAS for Mixed Models, 2nd edition. SAS Institute Inc, Cary, NC. 2006.

15. Sommer A. Ocular hypertension and normal-tension glaucoma. Time for banishment and burial. Arch Ophthalmol. 2011;129(6):785-787.

16. Aponte EP, Diehl N, Mohney BG. Incidence and clinical characteristics of childhood glaucoma: a population-based study. Arch Ophthalmol. 2010;128(4):478-482.

17. http:/quickfacts.census.gov. US Census Bureau. Available from: http:// quickfacts.census.gov/qfd/states/48/4827000.html. Accessed February 26, 2013.

18. Varma R, Ying-Lai M, Francis B, et al. Prevalence of open-angle glaucoma and ocular hypertension in Latinos. The Los Angeles Latino Eye study. Ophthalmology. 2004;111(8):1439-1448.

19. Tielsch JM, Sommer A, Katz J, et al. Racial variations in the prevalence of primary open-angle glaucoma. The Baltimore Eye Survey. JAMA. 1991;266(3):369-374.

20. Wood DL, Hayward RA, Corey CR, Freeman HE, Shapiro MF. Access to medical care for children and adolescents in the United States. Pediatrics. 1990;86(5):666-673.

21. Alanazi FF, Song JC, Mousa A, et al. Primary and secondary congenital glaucoma: baseline features from a registry at King Khaled eye specialist hospital, Riyadh, Saudi Arabia. Am J Ophthalmol. 2013;155: 882-889.

22. Tielsch JM, Katz J, Sommer A, Quigley HA, Javitt JC. Family history and risk of primary open angle glaucoma. The Baltimore Eye Survey. Arch Ophthalmol. 1994;112(1):69-73.

23. El-Dairi MA, Asrani SG, Enyedi LB, Freedman SF. Optical coherence tomography in the eyes of normal children. Arch Ophthalmol. 2009;127(1):50-58.

24. Papadopoulos M, Cable N, Rahi J, Khaw PT. The British infantile and childhood glaucoma (BIG) eye study. Invest Ophthalmol Vis Sci. 2007;48:4100-4106. 
25. Ayanniyi AA, Olatunji FO, Mahmoud AO, Ayanniyi RO. Clinical findings among Nigerian pediatric glaucoma suspects during a school eye health survey. The Open Ophthalmology Journal. 2008;2:137-140.

26. Abah ER, Oladigbolu KK, Samalia E, Gani-Ikilama A. Ocular disorders in children in Zaria children's school. Niger J Clin Pract. 2011;14(4):473-476.
27. Idrees F, Vaideanu D, Fraser SG, Sowden JC, Khaw PT. A review of anterior segment dysgeneses. Surv Ophthalmol. 2006;51(3):213-231.

\section{Publish your work in this journal}

Clinical Ophthalmology is an international, peer-reviewed journal covering all subspecialties within ophthalmology. Key topics include: Optometry; Visual science; Pharmacology and drug therapy in eye diseases; Basic Sciences; Primary and Secondary eye care; Patien Safety and Quality of Care Improvements. This journal is indexed on

Submit your manuscript here: http://www.dovepress.com/clinical-ophthalmology-journal

\section{Dovepress}

PubMed Central and CAS, and is the official journal of The Society of Clinical Ophthalmology (SCO). The manuscript management system is completely online and includes a very quick and fair peer-review system, which is all easy to use. Visit http://www.dovepress.com/ testimonials.php to read real quotes from published authors. 